\title{
Novel Treatment of Cancer and its Potential in Obesity: "Xeronine" Found in Morinda Citrifolia (Noni Fruit)
}

\section{Nirav R Soni ${ }^{*}$}

Department of Quality Assurance (QA), GTU, Ahmedabad A-one Pharmacy College, Ahmedabad, India

*Corresponding author: Nirav R Soni, Department of Quality Assurance (QA),GTU, Ahmedabad A-one Pharmacy college, Ahmedabad, India, Tel: +91 9033002567; Email: nirav_sonic@yahoo.com

Received date: January 03, 2018; Accepted date: January 08, 2018; Published date: January 15, 2018

Copyright: (C) 2018 Soni NR. This is an open-access article distributed under the terms of the Creative Commons Attribution License, which permits unrestricted use, distribution, and reproduction in any medium, provided the original author and source are credited.

Citation: Soni NR (2018) Novel Treatment of Cancer and its Potential in Obesity: "Xeronine" Found in Morinda Citrifolia (Noni Fruit). J Nutr Disorders Ther 8: e135. doi: $10.4172 / 2161-0509.1000$ e135

\section{Editorial}

Morinda citrifolia (family-rubiaceae) is one of the immense beneficial plants have been used by polynesia over an era of two thousand years. It is an evergreen minuscule sized tree, with shiny and deeply veined leaves found in tropical regions and islands of South Pacific, India, West Indies, Africa, and Australia. Noni fruit juice conventionally has been used in special disorders such as uneven or atypical menstruation, acne/boils, diarrhea and hard stool formation, autoimmune rheumatoid arthritis, hyperglycemia, fever, tachycardia, peptic ulcers, anxiety and other psychological disorder, poor or improper digestion, hyperlipidemia, blood vessel troubles, and drug obsession. Noni consists of chief constituents for example alkaloid xeronine (a widely play role), scopoletin, and dammacanthol, besides this is also contained vitamin $\mathrm{A}$ and $\mathrm{C}$ and minerals such as magnesium, potassium and ferric, amino acids, alizarin, ursolic acids. The article concluded that the pharmacological action and traditional uses of noni along with the scientific researchers and novel therapy to care for cancers and different neurological disorders (Figure 1).

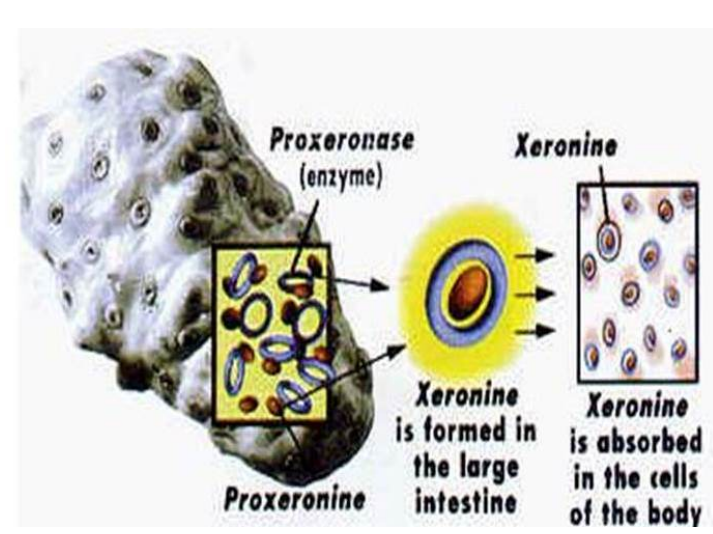

Figure 1: Cellular ion channels.
Noni can slow down cancer via inhibition of RAS a GTP binding protein and by alteration of the misfolded protein by one of its constituent named xeronine. It's opening cellular ion channels so that nutrients can enter cells in better way and helps cell to understand neuro-hormonal signals in a better way. It also shows anti-angiogenic property via COX-2 inhibition, which is a confident properties in the recent treatment of cancer patients. On the other hand, in obesity and its related indigestion, other studies are necessary to elucidate noni's mechanisms of action, for the most part due to the complexity of the pathophysiology of obesity and its indigestion problem. However, in obesity and obesity-related metabolic abnormalities. Noni has confirmed positive effects in indigestion, including the regulation of body weight and fat deposits, sugar and lipid metabolism and blood pressure, hepato-protective effects, and improvement in bacterial colonization of the gut and intestinal morphology. Though, Noni has never been the significant food plant, almost certainly due to its deprived palatability and toxicity, in its natural homeland. This summarize the persuade of the noni plant and its chemical components, promoting the probable mechanisms of action and effects on cell signaling pathways concerned in obesity related deficiency. This plant may be processed for some potential medicinal properties after the supervision of toxicity, or some parts of the plant may be mixed with less nutritional, but appetizing, food for health beneficiary effects. Therefore, doses and the time of treatment or long-term supplementation, and also new alternatives in the near future to improve the bioavailability of the product, are very large issues to be evaluated. Finally, since Morinda citrifolia contains imperative bioactive compounds for health, it may be an option therapeutic resource with great prospective in the treatment of obesity and obesityrelated metabolic problem or indigestion. 